Text bin ich bestrebt gewesen, das Verständnis des Gesagten und die festere Einprägung desselben in das Gedächtnis zu erleichtern. So hoffe ich denn, daB das vorliegende Lehrbuch der allgemeinen Chirurgie in der Tat den Bedürfnissen der Ärzte und der Studierenden möglichst entsprechen wird.

Leipzig, im September 1887.

Professor Dr. Herm. Tillmanns.

\title{
Vorwort zur zehnten Auflage.
}

Die zehnte Auflage meines Lehrbuchs der allgemeinen Chirurgie erscheint in wesentlich verbesserter Form, sie ist von Grund aus umgearbeitet worden, die neueste Literatur wurde sorgfältigst berücksichtigt, im Text finden sich zahlreiche Literaturangaben. Der Umfang der neuen Auflage meines Lehrbuches hat um 26 Seiten zugenommen, die Zahl der Abbildungen beträgt 787 (gegen 628 der vorigen Auflage).

$\mathrm{Zu}$ besonderem Danke bin ich Herrn Dr. PreindlsBerger in Sarajevo verpflichtet, welcher mir aus seiner reichhaltigen Sammlung von Abbildungen einige für mein Lehrbuch überlassen hat, ferner meinem ersten Assistenten Herrn Oberarzt Dr. KLARE, welcher mich bei den Korrekturen bestens unterstützte.

Leipzig, im März 1907.

H. Tillmanns. 